
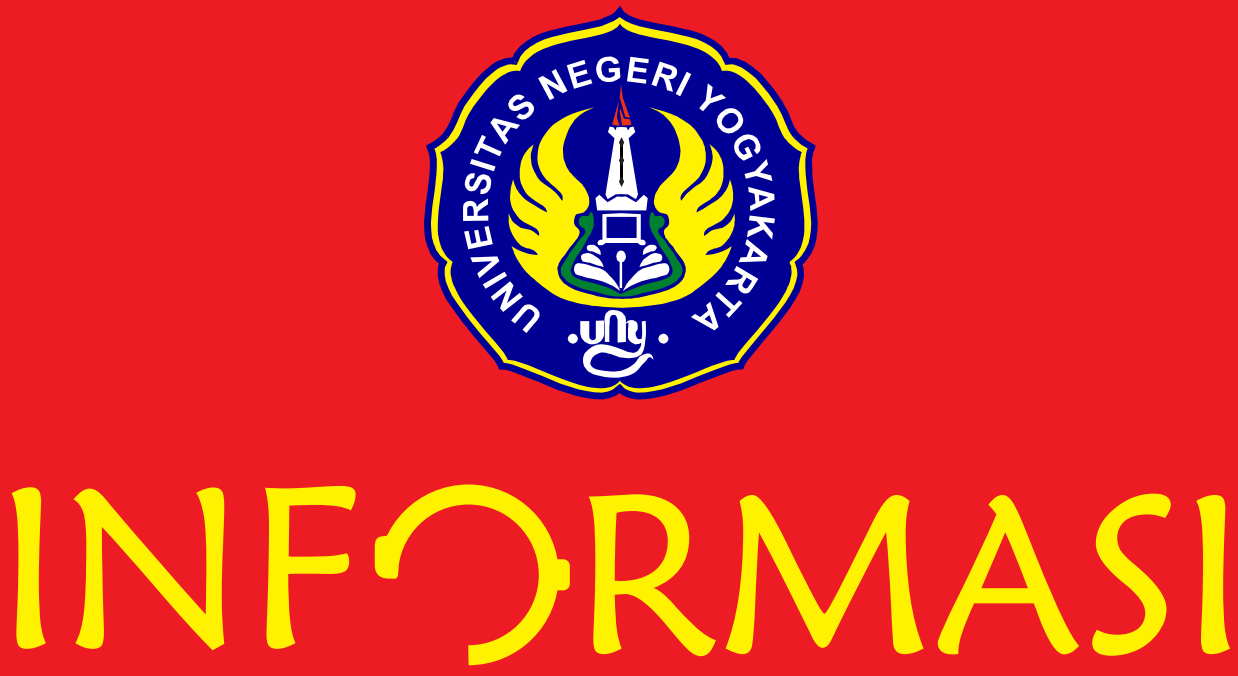

KAJIAN ILMU KOMUNIKASI

\author{
Diterbitkan \\ Jurusan Ilmu Komunikasi \\ Fakultas IImu Sosial \\ Universitas Negeri Yogyakarta
}




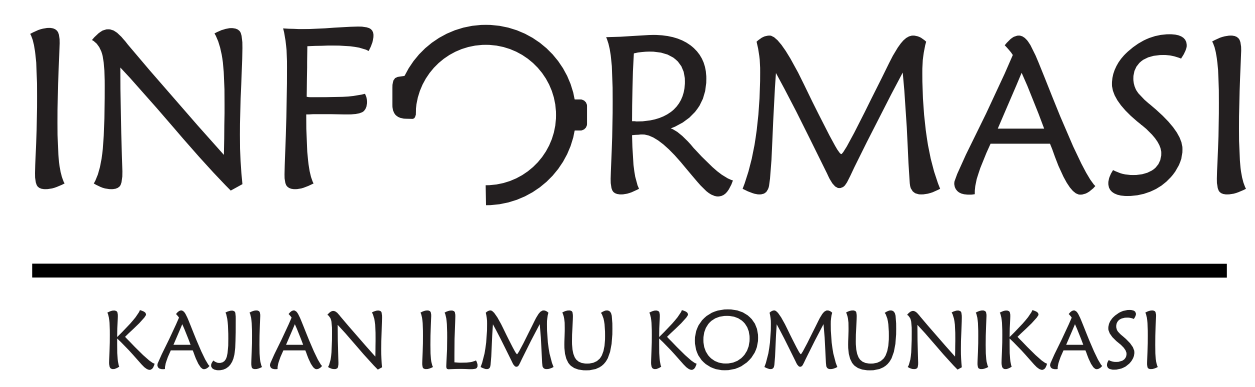

\title{
EDITORIAL TEAM
}

\author{
Editor in Chief \\ Benni Setiawan (Universitas Negeri Yogyakarta) \\ Editorial Board \\ Suranto Aw (Universitas Negeri Yogyakarta) \\ Novi Kurnia (Universitas Gadjah Mada) \\ Adi Nugroho (Universitas Diponegoro) \\ Nina Mutmainah (Universitas Indonesia) \\ Edwi Arief Sosiawan (Universitas Pembangunan Nasional Yogyakarta) \\ Hanny Haniar (Universitas Padjajaran) \\ Ni Made Ras Amanda G (Universitas Udayana)

\section{Editors} \\ Inaya Rakhmani (Universitas Indonesia) \\ Taufiqur Rahman (Universitas Muhammadiyah Yogyakarta) \\ Lily El Ferawati Rofil (Universitas Negeri Yogyakarta) \\ Rama Kerta Mukti (Universitas Islam Negeri Sunan Kalijaga Yogyakarta) \\ Yuliyanto Budi Setiawan (Universitas Semarang) \\ Chatia Hastasari (Universitas Negeri Yogyakarta) \\ Agus Triyono (Universitas Muhammadiyah Surakarta) \\ Dyna Herlina Suwarto (Universitas Negeri Yogyakarta) \\ S. Bekti Istiyanto (Universitas Jenderal Soedirman)

\section{Managing Editor} \\ Siti Machmiyah (Univeritas Negeri Yogyakarta)
}

\section{Alamat Redaksi}

Jurusan Ilmu Komunikasi Fakultas Ilmu Sosial

Universitas Negeri Yogyakarta Kampus Karangmalang, G.o1. Lantai 2 FIS

(o274) 548820 Psw.450 Email: s1komunikasi@uny.ac.id, informasi.ilkomuny@gmail.com

INFORMASI adalah jurnal yang diterbitkan oleh Jurusan Ilmu Komunikasi Fakultas Ilmu Sosial Universitas Negeri Yogyakarta. Jurnal ini dimaksudkan sebagai media publikasi, penelitian, pertukaran ide, dan kajian, di samping sebagai penyalur informasi dan pengembangan ilmu komunikasi.

INFORMASI mengangkat tema-tema khusus dan memuat tulisan ilmiah yang ditujukan untuk kalangan akademisi, praktisi, dan masyarakat pada umumnya. Tulisan yang dimuat dalam jurnal INFORMASI telah melalui mekanisme penyuntingan seperlunya tanpa mengubah substansi naskah asli. Isi tulisan yang dimuat dalam jurnal ini merupakan pendapat personal dan menjadi tanggung jawab penulisnya. 



\section{INFつRMASI KAJIAN ILMU KOMUNIKASI}

\section{DAFTAR ISI}

EVALUASI PROGRAM DESA MANDIRI INFORMASI BERBASIS APLIKASI

ANDROID SISTEM INFORMASI DESA (SIFORDES)

Oleh Suranto Aw 1-14

STRATEGIZING SMALL AND MEDIUM ENTERPRISES DEVELOPMENT THROUGH ICT-RELATED INNOVATIONS ADOPTION:

Moderating Influence of Gender, Age and Experience

Oleh Adamkolo Mohammed Ibrahim $.15-32$

AN INITIAL EXPLORATION ON TERRORISM ISSUES IN MALAYSIA AND INDONESIA: The Case of the Wall Street Journal

Oleh Fauziah Hassan, Sofia Hayati Yusoff, dan Siti Zobidah Omar $33-48$

STRUKTURASI KOMUNIKASI INTERNAL DALAM PRAKTIK MEDIA RELATIONS DI DALAM INDUSTRI MEDIA

Oleh Brahma Putra Pratama $49-64$

BAHASA ISYARAT INDONESIA SEBAGAI BUDAYA TULI MELALUI PEMAKNAAN ANGGOTA GERAKAN UNTUK KESEJAHTERAAN TUNA RUNGU

Oleh Gilang Gumelar, Hanny Hafiar, dan Priyo Subekti $65-78$

\section{COUNTER HEGEMONI ATAS OTORITAS AGAMA PADA FILM} (ANALISIS WACANA KRITIS FAIRCLOUGH PADA FILM SANG PENCERAH)

Oleh Syifaul Fauziyah dan Kharisma Nasionalita $79-94$

GENERASI MILENIAL DAN ABSURDITAS DEBAT KUSIR VIRTUAL

Oleh Noveliyati Sabani $.95-108$

ANALISIS BINGKAI PEMBERITAAN AKSI BELA ISLAM 2 DESEMBER 2016 (AKSI 212) DI MEDIA MASSA BBC (INDONESIA) \& REPUBLIKA

Oleh Abidatu Lintang Pradipta, Nadya Warih Nur Hidayah, Afifah Nafiatun Annisa Haya, Carissa Ervania, dan Deny Kristanto .109-124 
KPK: KORBAN BALAS DENDAM POLRI (Analisa Naratif Model Greimas Pada Karakter KPK dan Polri di Majalah Tempo)

Oleh Anastasia Yuni Widyaningrum dan Noveina Silviyani Dugis $125^{-138}$

KONSTRUKSI MEDIA DALAM PEMBERITAAN KONTRA TERORISME DI INDONESIA

Oleh Mubarok dan Diah Wulandari 139-152 